Table 1. Initial demographic and clinical datas of patients with PsA

\begin{tabular}{|c|c|}
\hline & PsA Patients $(n=355$ \\
\hline Females, n (\%) & $227(63,9)$ \\
\hline Age of diagnosis, years* & $34,6(27-42)$ \\
\hline CRP baseline* & $6 \mathrm{mg} / \mathrm{L}(3-15)$ \\
\hline ESR baseline* & $24 \mathrm{~mm} / \mathrm{h}(10-38)$ \\
\hline \multicolumn{2}{|l|}{ Smoking, n (\%) } \\
\hline Current & $99(28,5)$ \\
\hline Never & $192(55,3)$ \\
\hline Previous & $56(16,2)$ \\
\hline HLA B27 positivity,n (\%) & $41(26,4)$ \\
\hline \multicolumn{2}{|l|}{ First biologic agent, $n(\%)$} \\
\hline -TNFi & $332(95,4)$ \\
\hline Adalimumab & $125(37,6)$ \\
\hline Etanercept & $80(24,1)$ \\
\hline Golimumab & $52(15,6)$ \\
\hline Certolizumab & $44(13,3)$ \\
\hline Infliximab & $31(9,4)$ \\
\hline - Other biologic agents & $16(4,6)$ \\
\hline Secukinumab & $13(81,3)$ \\
\hline Ustekinumab & $3(18,7)$ \\
\hline
\end{tabular}

* median (min-max)

Conclusion: The results of this study establish that more than half of patients with PsA can remain in their initial biologic treatment over a long term. It has been observed that the choice of biologic treatment did not effect the drug survival in PsA.

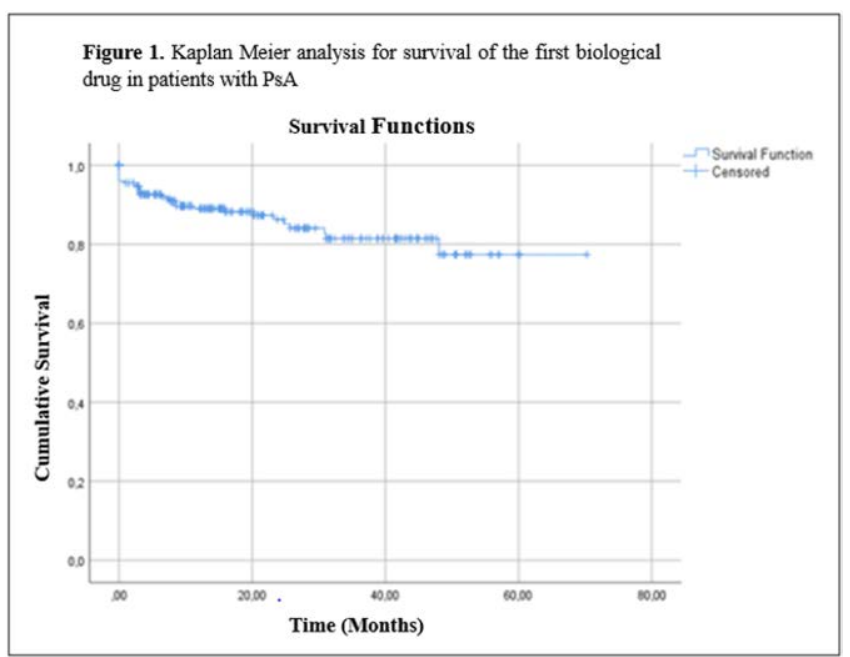

Disclosure of Interests: None declared

DOI: 10.1136/annrheumdis-2020-eular.3909

\section{SAT0424 OBESITY LINKS TO PSORIATIC ARTHRITIS (PSA) ACTIVITY, HIGHER PREVALENCE OF CARDIOMETABOLIC DISORDERS AND WORSE PATIENT REPORTED OUTCOMES (PROS): DATA FROM THE RUSSIAN PSA REGISTRY (RU-PSART)}

Y. Korsakova $^{1}$, E. Loginova ${ }^{1}$, E. Gubar ${ }^{1}$, E. Vasilenko ${ }^{2}$, A. Vasilenko ${ }^{3}$, N. Kuznetsova ${ }^{4}$, I. Patrikeeva ${ }^{5}$, T. Korotaeva ${ }^{6}$, A. Lila ${ }^{7}$, E. Nasonov ${ }^{7}$ ' RU-PsART Study Group. ${ }^{1}$ V.A. Nasonova Research Institute of Rheumatology, Department of Spondyloarthritis and Psoriatic Arthritis, Moscow, Russian Federation; ${ }^{2}$ Clinical Rheumatological Hospital №25, St Petersburg, Russian Federation; ${ }^{3}$ Novgorod Regional Clinikal Hospital, Novgorod, Russian Federation; ${ }^{4}$ Municipal Autonomous Institution "City Clinical Hospital No. 40", Ekaterinburg, Russian Federation; ${ }^{5}$ Tyumen Regional Clinical Hospitai №1, Tyumen, Russian Federation; ${ }^{1}$ V.A. Nasonova Research Institute of Rheumatology, Department of Spondyloarthritis and Psoriatic Arthritis, Moscow, Russian Federation; ${ }^{7}$ V.A. Nasonova Research Institute of Rheumatology, Moscow, Russian Federation

Background: PsA patients (pts) have an increased risk of cardiovascular (CV) and metabolic (Met) disorders due to the combination of inflammation and increased prevalence of traditional CV risk factors. Only limited data are available on Russian PsA pts. Data was collected from 25 rheumatology clinics of the Russian Federation

Objectives: to study, in clinical practice, the prevalence of obesity and its association with PsA activity, CV/Met comorbidities and PROs
Methods: $614(\mathrm{M} / \mathrm{F}=331(54 \%) / 283(46 \%) \mathrm{PsA}$ pts fulfilling the CASPAR criteria were included from the RU-PsART cohort. Mean age $45.2 \pm 0.52 \mathrm{yrs}$, PsA duration 5.7 $\pm 0.27 \mathrm{yrs}$, PsO duration $15.71 \pm 0.56 \mathrm{yrs}$, DAPSA $28.79 \pm 0.75$. At baseline (BL) PsA activity was evaluated by Tender Joint Count (TJC68), Swollen Joint Count (SJC66), PGA, physician global assessment by Visual Analog Scale (VAS), DAPSA; PROs according to PtGA VAS, PtPain VAS, HAQ, Work Productivity and Activity Index (WPAI) and Body Mass Index (BMI, $\mathrm{kg} / \mathrm{m}^{2}$ ) were calculated. All pts were split into three groups by BMl $\left(\mathrm{kg} / \mathrm{m}^{2}\right)$ : normal<25 (I group), overweight 25-30 (II group), obese>30 (III group). M mm, \%, Me [Q25; Q75], $x^{2}$ or Fischer's exact tests were performed

Results: At BL the BMI was $27.7 \pm 0.23 \mathrm{~kg} / \mathrm{m}^{2}$ with the following BMI categories: normal - 213 pts (34.7\%), overweight - 214 pts (34.8\%) and obese - 187 (30.5\%) Increased BMI was observed in $65.3 \%$ of PsA pts. In all groups, comorbidities were found in 297 out of 614 pts (48\%): arterial hypertension in 190 (64\%) diabetes mellitus in $44(14.8 \%)$, Met syndrome in $36(12.1 \%)$, Coronary Heart Disease in 22 (7.4\%). CV and Met disorders were significantly more common in obese pts with $\mathrm{BMI}>30$ compared to overweight pts and to normal BMI pts; female prevailed (Table 1).

Table 1. CV/Met comorbidity in three groups, $\mathrm{n}(\%)$.

\begin{tabular}{lcccc}
\hline & $\begin{array}{c}\text { I group } \\
\text { BMI }<25 \mathrm{~kg} / \mathrm{m}^{2}\end{array}$ & $\begin{array}{c}\text { II group } \\
\text { BMI } 25-30 \mathrm{~kg} / \mathrm{m}^{2}\end{array}$ & $\begin{array}{c}\text { III group } \\
\text { BMI }>30 \mathrm{~kg} / \mathrm{m}^{2}\end{array}$ & $\mathrm{p}$ \\
\hline Arterial hypertension & $28(13.2)$ & $55(25.7)$ & $85(46.5)$ & $\mathrm{p}<0.0001^{*}$ \\
Diabetes mellitus & 0 & $15(7)$ & $25(14)$ & $\mathrm{p}<0.0001^{* *}$ \\
Metabolic syndrome & $0(0)$ & $6(2.8)$ & $23(12.8)$ & $\mathrm{p}<0.0001^{* *}$ \\
Coronary heart disease & $2(0.9)$ & $6(2.8)$ & $10(5.6)$ & $\mathrm{p}<0.026^{\star * *}$
\end{tabular}

*III vs I and II groups, ${ }^{* *}$ III vs II, *** III vs I group

At $\mathrm{BL}$ pts with $\mathrm{BMl}>30$ had higher PsA activity by DAPSA, HAQ, daily activity impairment by WPAI, PtPin compared to I and II groups (table 2).

Table 2. PsA activity and PROs based on BMI categories.

\begin{tabular}{lcccc}
\hline & $\begin{array}{c}\text { I group } \\
\mathrm{BMI}<25 \mathrm{~kg} / \mathrm{m}^{2}\end{array}$ & $\begin{array}{c}\text { II group } \\
\mathrm{BMI} 25-30 \mathrm{~kg} / \mathrm{m}^{2}\end{array}$ & $\begin{array}{c}\text { III group } \\
\mathrm{BMI}>30 \mathrm{~kg} / \mathrm{m}^{2}\end{array}$ & $\mathrm{p}$ \\
\hline DAPSA & $22.7[14.7 ; 35.8]$ & $24.9[13.5 ; 38.5]$ & $27[17.2 ; 44.4]$ & $\mathrm{p}<0,05^{*}$ \\
HAQ & $0.9[0.5 ; 1.3]$ & $0.9[0.5 ; 1.3]$ & $1[0.8 ; 1.6]$ & $\mathrm{p}<0,05^{*}$ \\
Daily activity impairment & $0.3[0 ; 0.5]$ & $0.3[0 ; 0.5]$ & $0.4[0 ; 0.6]$ & $\mathrm{p}<0,05^{*}$ \\
PtPain, mm VAS & $50[30 ; 66.5]$ & $50[30 ; 68]$ & $50[40 ; 70]$ & $\mathrm{p}<0,05^{* *}$ \\
\hline
\end{tabular}

${ }^{*} \mathrm{p}<0.05$ III vs I and II groups, ${ }^{* *} \mathrm{p}<0.05$ III vs II group

Conclusion: In clinical practice, BMI increase was found in the majority of PsA pts. Obesity was associated with higher PsA activity, more prevalence of CV/ Met disorders and worse PROs. Obesity requires a change of the pts' lifestyle, nutrition correction and a right choice of therapy

Disclosure of Interests: Yulia Korsakova: None declared, Elena Loginova Speakers bureau: Janssen, ELENA GUBAR: None declared, Elizaveta Vasilenko: None declared, Aleksey Vasilenko: None declared, Natalia Kuznetsova: None declared, Irina Patrikeeva: None declared, Tatiana Korotaeva Grant/research support from: Pfizer, Consultant of: Abbvie, BIOCAD, Bristol-Myers Squibb Celgene, Eli Lilly, Janssen, Merck Sharp \& Dohme, Novartis, Novartis-Sandoz, Pfizer, UCB, Speakers bureau: Abbvie, BIOCAD, Bristol-Myers Squibb, Celgene, Eli Lilly, Janssen, Merck Sharp \& Dohme, Novartis, Novartis-Sandoz, Pfizer, UCB, Alexander Lila: None declared, Evgeny Nasonov: None declared DOI: 10.1136/annrheumdis-2020-eular.5538

\section{SAT0425 NOVEL COMPUTER-ASSISTED METHODOLOGY FOR QUANTITATIVE ASSESSMENT OF MRITREATMENT RESPONSES TO APREMILAST IN PATIENTS WITH PSORIATIC ARTHRITIS}

P. Bird ${ }^{1}$, M. Boesen ${ }^{2}$, M. Hinton ${ }^{3}$, E. Sanverdi ${ }^{3}$, R. Hagoug ${ }^{3}$, C. Sabin ${ }^{3}$ P. Nakasato ${ }^{4}$, B. Guerette ${ }^{4}$, O. Kubassova ${ }^{3} .{ }^{1}$ Optimus Research, New South Wales, Australia; ${ }^{2}$ Copenhagen University Hospital Bispebjerg-Frederiksberg, Department of Radiology, Copenhagen, Denmark; ${ }^{3}$ Image Analysis Group (IAG), London, United Kingdom; ${ }^{4}$ Celgene Corporation, Summit, United States of America

Background: Response to treatment in psoriatic arthritis (PsA) can be captured using the OMERACT PsA Magnetic Resonance Imaging Score (PSAMRIS). While reliable and valid, PSAMRIS interpretation requires a trained reader to assess inflammatory lesions such as synovitis and flexor tenosynovitis on a discrete scale ranging from 0 to 3 , which might not have sufficient sensitivity to capture early and subtle changes in inflammation in small cohorts. 
Objectives: To propose a novel computer-assisted imaging quantitative methodology to assess early response to treatment on a continuous scale and compare its results with those of PSAMRIS.

Methods: Patients with active PsA in the hand and wrist were treated with apremilast $30 \mathrm{mg}$ twice daily after a 5-day titration period. A total of 29 patients underwent MRI scans at baseline and months 3, 6, and 12. Images were scored for synovitis using the PSAMRIS interpreted by an experienced reader and were read in blinded sequences. Images for 13 patients with involvement of the wrist and metacarpophalangeal (MCP) joints and MRI available at baseline, 3 months, and 6 months were further processed using a novel computer-assisted imaging quantitative methodology. Images were scored concurrently, with the reader blinded to the order of visits. An experienced reader pre-defined regions of interest (ROIs) around the wrist, MCP joints (MCP-2 to MCP-5), and flexor and extensor tendons of the fingers and wrist (as applicable) with adjacent blood vessels and possible artifacts excluded from ROls. From these ROls, the normalized volume of inflammation (Norml) was calculated in each joint and tendon. This was done by automatically counting the pixels that were enhanced above the intensity level of a muscle. Each enhanced pixel was given a weight corresponding to the degree of enhancement, allowing differentiation of areas of residual inflammation and high perfusion. This method has been validated, tested, and implemented in the CE/FDA510-cleared software package Dynamika (IAG, Image Analysis Group). PsAMRIS responses were compared with those of the computer-assisted imaging quantitative methodology at baseline, 3 months, and 6 months. A heat map of normalized intensities was produced, highlighting areas of perfusion higher than that of healthy muscle. Changes from baseline were tested for significance using a $t$-test. Patients with non-missing data were included in the final statistical analysis.

Results: The generated Norml map highlighted a reduction in wrist inflammation activity after 3 and 6 months of treatment with apremilast. In all cases, a downward trend in inflammatory activity in the wrist and MCP joints was observed at 3 months, indicating a reduction following treatment with apremilast (Figures 1 and 2). Similar improvements were observed in tenosynovitis (Figures 1 and 2). Conclusion: In this pilot assessment, apremilast was associated with improvements in synovitis and tenosynovitis over a period of 6 months using PsAMRIS. Assessment of images using Norml, a methodology allowing quantification of inflammatory activity within a joint or tendon, demonstrated the same trends over 6 months. Further studies are planned to determine the sensitivity of this novel computer-assisted imaging quantitative methodology relative to that of PSAMRIS and whether it could be used to provide early indications of treatment response in small cohorts of patients.

Figure 1. NormI Mean Intensity Values at Baseline, 3 Months, and 6 Months

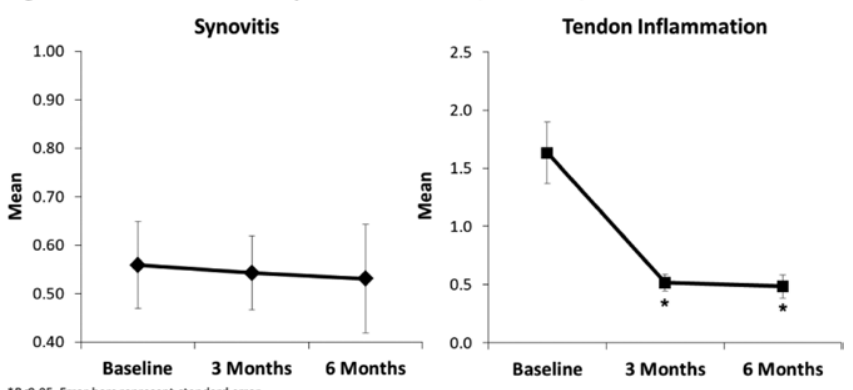

(2005.

Figure 2. PsAMRIS Mean Values at Baseline, 3 Months, and 6 Months
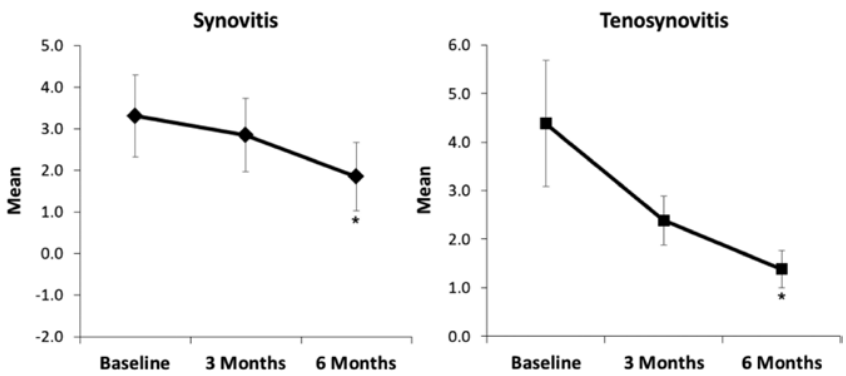

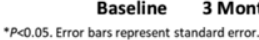

Disclosure of Interests: Paul Bird Consultant of: AbbVie, Celgene Corporation, Eli Lilly, Janssen, Novartis, Pfizer - advisor, Speakers bureau: AbbVie, Celgene Corporation, Eli Lilly, Janssen, Novartis, Pfizer, Mikael Boesen Consultant of: AbbVie, AstraZeneca, Eli Lilly, Esaote, Glenmark, Novartis, Pfizer, UCB, Paid instructor for: IAG, Image Analysis Group, AbbVie, Eli Lilly, AstraZeneca, esaote,
Glenmark, Novartis, Pfizer, UCB (scientific advisor)., Speakers bureau: Eli Lilly, Esaote, Novartis, Pfizer, UCB, Mark Hinton: None declared, Eser Sanverdi Employee of: Image Analysis Group - employment, Romiesa Hagoug Employee of: Image Analysis Group - employment, Christoper Sabin Employee of: Image Analysis Group - employment, Priscila Nakasato Employee of: Amgen Inc. employment; Celgene Corporation - employment at the time of study conduct, Benoit Guerette Employee of: Amgen Inc. - employment; Celgene Corporation - employment at the time of study conduct, Olga Kubassova Shareholder of: IAG, Image Analysis Group, Consultant of: Novartis, Takeda, Lilly, Employee of: IAG, Image Analysis Group

DOI: 10.1136/annrheumdis-2020-eular.1335

\section{SAT0426 CAN BIOLOGICS “PREVENT” THE DEVELOPMENT OF PSORIATIC ARTHRITIS IN PSORIASIS PATIENTS? DATA FROM A LARGE UNIVERSITY HOSPITAL COHORT IN ARGENTINA}

L. Lo Giudice ${ }^{1}$, M. L. Acosta Felquer ${ }^{1}$, M. L. Galimberti ${ }^{1}$, L. Mazzuoccolo ${ }^{1}$,

E. Soriano ${ }^{1}{ }^{1}$ Hospital Italiano de Buenos Aires, ABH, Argentina

Background: As psoriasis (Pso) commonly precedes psoriatic arthritis (PsA), an important unanswered question is whether treatment of Pso might influence the development of PsA in patients with psoriasis

Objectives: The objective of this study was to analyze the incidence of PsA in a large cohort of patients with $\mathrm{PsO}$ according to different treatments, with the hypothesis that treatment with biologics might prevent the development of PsA.

Methods: Patients with PsO without PsA followed at a University Hospital were included in this retrospective cohort study. Data was obtained from the Hospital Electronic Medical Record (EMR). Patients were classified according to their treatment in topics group (topic and phototherapy), conventional DMARDs (cDMARDs) group (Methotrexate (MTX) and cyclosporine (Cyc)), and biologic DMARDs group (bDMARDs) (TNFi, IL17i, and IL12-23i). Patients contributed time since beginning of the corresponding treatment until diagnosis of PsA lost of follow up, end of treatment or end of study. Incident cases of PsA were attributed to one treatment if developed during the administration of that treatment and up to 6 months after its discontinuation if no other treatment was started. Incident cases that developed more than one year after discontinuation of treatment were disregarded ( 3 cases). Incidence rate was calculated for the whole population and for each one of the treatment groups and compared with chi2test, and rate ratios were calculated as well. A multivariable logistic mode for the development of PsA was analyzed by treatment groups, adjusting by other variables.

\begin{tabular}{|c|c|c|c|c|}
\hline & $\begin{array}{l}\text { Topics, } \\
\mathrm{n}=599\end{array}$ & $\begin{array}{l}\text { cDMARDs, } \\
n=106\end{array}$ & $\begin{array}{l}\text { bDMARDs, } \\
n=92\end{array}$ & $\begin{array}{c}\text { Total group, } \\
\mathrm{n}=797\end{array}$ \\
\hline $\begin{array}{l}\text { Mean age at PsO diagnosis } \\
\text { (SD) }\end{array}$ & $43.6(20.6)$ & $46.2(20.7)$ & $35.1(18.9)$ & $42.9(20.6)$ \\
\hline Female, n (\%) & $314(52)$ & $53(50)$ & $36(39)$ & $403(50.5)$ \\
\hline Plaque PsO, n/N (\%) & $514 / 578(89)$ & $93 / 103(90)$ & $85 / 90(94)$ & $\begin{array}{c}692 / 771 \\
(90)\end{array}$ \\
\hline BMI, n; Mean (SD) & $498 ; 27.6(5.4)$ & $80 ; 28.5(5.6)$ & $91 ; 30(7)$ & $659 ; 28(5.7)$ \\
\hline N Developed PsA (\%) & $68(8.5)$ & $3(0.38)$ & $1(0.13)$ & $72(9)$ \\
\hline Follow up (patient/years) & 9153 & 316 & 548 & 10017 \\
\hline $\begin{array}{l}\text { Incidence rate/1000 Patient/ } \\
\text { years }(95 \% \mathrm{Cl})\end{array}$ & $7.4(5.8-9.4)$ & $9.5(1.9-27.5)$ & $1.81(0.04-10)$ & $7.2(5.6-9)$ \\
\hline $\begin{array}{l}\text { Median years between PsO } \\
\text { and PsA (IQR) }\end{array}$ & $10(2-21)$ & $\begin{array}{c}\text { Patient 1: } 23 \\
\text { Patient 2: } 11.7 \\
\text { Patient 3: } 24.7\end{array}$ & Patient (1): 9.6 & $\begin{array}{c}10.5 \\
(2-20.8)\end{array}$ \\
\hline
\end{tabular}

Results: 797 patients, contributed a total of 10017 patient/years. Patient's char acteristics are shown in table 1.599 (75\%) patients were treated only with topics or phototherapy, 106 (13\%) with cDMARDs (81\% MTX and 19\% Cyc) and 92 (11.5\%) with biologics (TNFi: 64 : etanercept: 44 , adalimumab:23, infliximab:6; IL17i: 43: 14 Ixekizumab, 29 Secukinumab; IL12-23i: (Ustekinumab) 16; some patients received more than one biologic). During follow-up 72 patients developed PsA (68 under topics; 3 under cDMARDs (2 MTX and 1 Cyc) and 1 under biologics (1 Secukinumab): Global incidence rate: 7.2 per 1000 patient/years (table 1). Although numerically the incidence of PsA in $\mathrm{PsO}$ patients treated with biologics was lower, the difference was not statistically significant. In Cox regression analysis, after adjusting by sex, age, and BMI, treatment with biologics was significantly associated with a reduced risk of developing PsA: Hazard ratio (95\% Cl): $0.1(0.013-0.7) ; p=0.021$.

Conclusion: Treatment with biologics in patients with $\mathrm{PsO}$ seemed to reduce the risk of PsA and preventing its development in this retrospective single center cohort.

Acknowledgments: This study was awarded with the PANLAR stimulus award 2019 